A AUTORA

Tânia Regina Gonçalves Figueiredo

Prof ${ }^{\circledR}$ da Escola Estadual de Ensino

Fundamental Antônio Gomes de Oliveira,

Marília, São Paulo

\title{
O JORNALISMO COMO FONTE DE ENSINO
}

Produção de jornal em sala de aula auxilia a criança a produzir textos espontâneos com seqüiência lógica

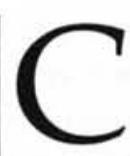

omo professora do ensino fundamental, trabalhando com alunos da $1^{a}$ à $4^{a}$ séries, procurei priorizar um projeto que utilizasse a linguagem escrita para que os alunos se sentissem estimulados a produzir textos e aprimorassem o conhecimento da língua portuguesa.

Através do Projeto Fazer, gostar e aprender: uma produção de jornal, trabalhei durante 2 meses com 34 alunos analisando estruturas de textos jornalísticos como recurso didático com o objetivo de sanar as dificuldades que as crianças têm para produzirem textos espontâneos com uma seqüência lógica.

O trabalho com a produção do jornal envolveu todos os alunos. Utilizamos diferentes tipos de textos como os classificados, propagandas, opinião do leitor, entre outros.

\section{AS ETAPAS DO PROJETO}

A partir de um jornal local da cidade de Marília e um que abrange o Estado de São Paulo, fomos desvendando para que serve um jornal - o que é, sua utilidade, as seções etc.

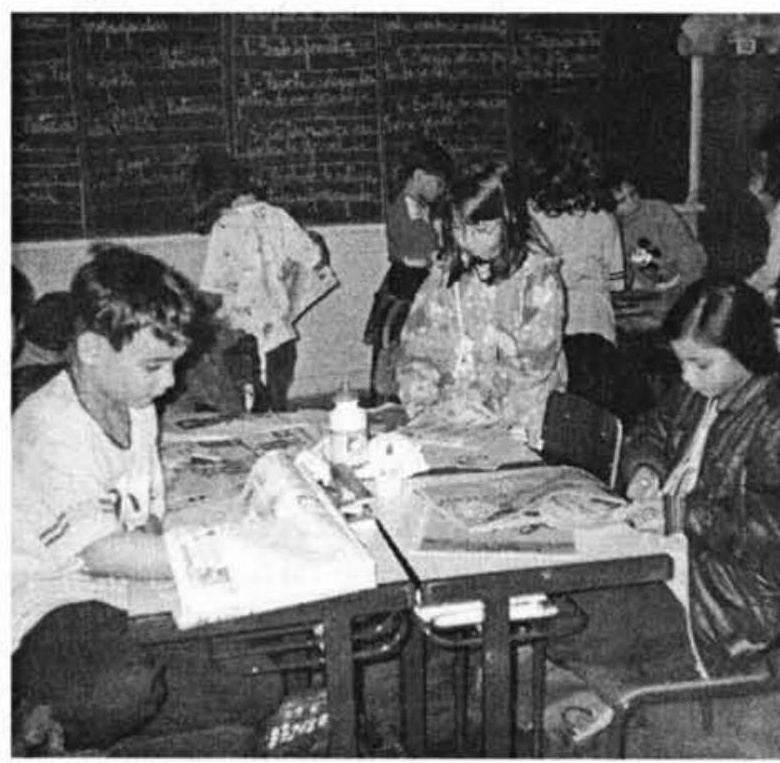

$1^{\text {a }}$ montagem do jornal. Cada grupo ficou com uma seção 
Para entender os textos, interpretá-los corretamente, parti para uma metodologia diferenciada em que utilizo como dinâmica de aprendizado as atividades de entretenimento como caça-palavras, a for$\mathrm{ca}$, a pesquisa, palavras-cruzadas.

Com recortes e colagens das partes dos jornais selecionados previamente, fomos aprendendo a manuseá-lo e a identificar cada parte. Utilizei também a confecção de cartazes a partir das seções do jornal, destacando e identificando os diferentes tipos de estrutura de textos encontrados, por exemplo, em anúncios e propagandas, notícias, reportagens, entre outros.

Formamos grupos de 3 a 4 alunos e nos dispusemos a confeccionar todos os tipos de textos aprendidos anteriormente. Cada aluno escolhia o tema que mais $\mathrm{o}$ interessou e produzia um artigo. Cada grupo ficou responsável por uma seção do jornal.

Depois nos reunimos para a escolha do nome do jornal, que foi unanimemente votado em Jornal da Classe. Para a montagem do Jornal da Classe utilizamos papel pardo em folhas grandes, procurando usar algumas seções prontas dos jornais selecionados para a pesquisa dos textos.

Todo o processo de redação de textos, montagem das seções, revisão dos artigos e confecção da capa foi realizado em conjunto entre os grupos de alunos.

Procurei documentar todas as atividades desenvolvidas pelos alunos através da fotografia, o que no final gerou uma exposição fotográfica, através da qual pais e mães puderam vivenciar a experiência de seus filhos.

Essa primeira etapa do trabalho foi o pontapé inicial para que ao longo do ano

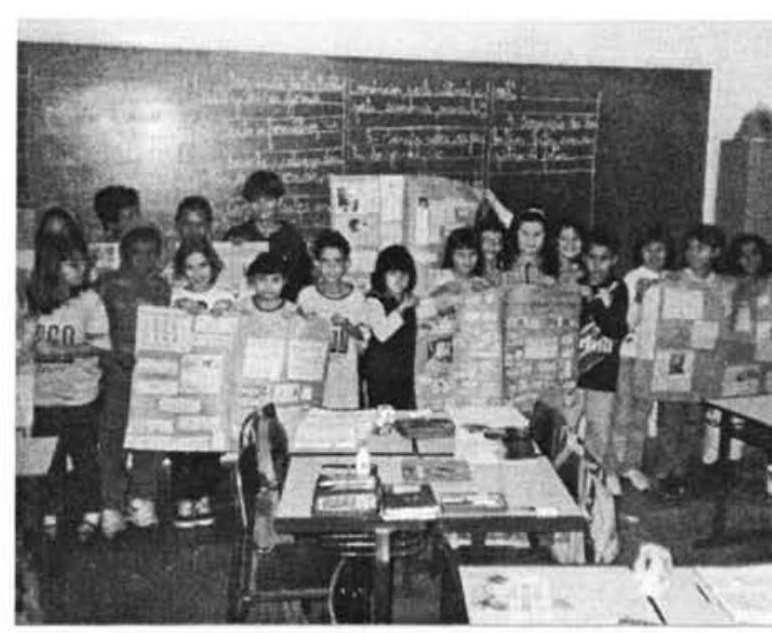

Finalização do Jornal da Classe

letivo sejam feitas pesquisas paralelas aos demais conteúdos programados, com reportagens de assuntos variados como: educação, saúde, trabalho, meio ambiente etc., podendo ser aproveitados e estudados a partir das disciplinas de história, geografia, matemática, ciências, saúde e educação artística.

Fazer, gostar e aprender: uma

produção de jornal é um

projeto interdisciplinar e tem

como objetivo principal dar

conta da produção dos

diferentes tipos de estrutura de textos que tanto são trabalhados em português.

Também estimula os alunos na produção espontânea de textos e dá início a uma nova dinâmica de trabalho de investigação com pesquisa, interpretação, reescritas, desenhos e experiências com produção. 
A segunda etapa do trabalho segue pelo segundo semestre com as atividades de pesquisa, consulta de artigos, interpretação e resumo de reportagens, produções variadas, estudo de dados matemáticos como análises de gráficos, leitura de legendas, culminando com a produção do segundo jornal da classe em outubro, novembro do ano corrente.

\section{RESULTADOS}

Os resultados obtidos com a realização desse trabalho são bastante satisfatórios, pois até os alunos com defasagem no

Resumo: Professora da rede pública de ensino conta sua experiência pedagógica desenvolvendo projeto que utiliza a elaboração de um jornal como fonte de aprendizado para textos espontâneos com seqüência lógica. As crianças aprendem a ler o jornal, a entender o que são as seções, como elas se distribuem, o que é editorial, opinião do leitor, discutem entre si, criam novas matérias, selecionam os assuntos preferidos, utilizam colagens. Além de aprenderem a escrita espontânea, a professora trabalhou com as crianças noçōes de diagramação, de elaboração gráfica, à medida que elas tinham que montar o Jornal da Classe para depois ser colocado à disposição das outras classes da escola e também para observarem o trabalho produzido

Palavras-chave: jornal, projeto pedagógico, elaboração de textos, diagramação, ensino fundamental aprendizado e dificuldade na produção espontânea de textos participam, desenvolvem sua capacidade de criar e adquirem gosto pela produção, tornando-se capazes de avaliar seu próprio progresso.

Portanto, esse projeto cumpre a função de fornecer um suporte para a construção da aprendizagem de forma elaborada, criativa e gostosa para o aluno, tornando-o conhecedor de temas atuais e importantes do seu dia-a-dia, dando assim condições ao mesmo de interagir no meio em que vive, inclusive como agente portador de opiniões, informações e conhecimento.
(Journalism as a source of teaching) Abstract. A teacher of the public school network talks about her teaching experience developing a project that uses the elaboration of a newspaper as a source of learning how to write spontaneous texts with logical sequences. The children learn how to read the newspaper, to understand its sections and how they are distributed, what an editorial note is, and even the reader's opinion. They discussed themes among each other, created new articles, selected their preferred subjects, and used collage. Aside from learning spontaneous writing, the teacher also worked on notions of newspaper layout and graphic elaboration with the children while the Class Newspaper was being put together. The final product was then shown to the other classrooms in the school so they could also see the work that had been done.

Key words: newspaper, teaching project, elaborating texts, layout, elementary school 